\title{
Accuracy of 7-8-9 Rule: Neonatal Endotracheal Intubation
}

\author{
J Nepal Paediatr Soc September- December, 2011/Volume 31/Issue 3 \\ Sakhuja $\mathrm{P}^{1}$, Whyte $\mathrm{H}^{2}$, Finan $\mathrm{E}^{3}$ \\ 'Dr. Pankaj Sakhuja, Clinical fellow, Acute Care Transport Service, Division of Neonatology, The Hospital for Sick Children, \\ Toronto, Ontario, Canada. ${ }^{2}$ Dr. Hilary Whyte (Medical Director), Acute care transport service, Division of Neonatology, The \\ Hospital for Sick Children, Toronto, Ontario, Canada, ${ }^{3}$ Dr. Emer Finan, Neonatologist, Mt Sinai Hospital, Toronto, Ontario, \\ Canada
}

Address for correspondence: Dr. Pankaj Sakhuja, E-mail: Pankaj.sakhuja@sickkids.ca

$\mathrm{D}$ Paudel's observational study highlights the challenges encountered in placement of endotracheal tube in neonatal ICU especially in extreme premature infants where the trachea is much shorter, leaving little margin of error.

The rule of 7-8-9 was suggested by Tochen in 1979 with reference to T1-T2 as a midtracheal position ${ }^{4}$. The newborn larynx is positioned higher in the neck, it extends from C 3 to $\mathrm{C} 5$ and carina is situated between T3-T5 and most commonly at T4 $4^{1,5,6}$. If this information is to be collated then the midpoint of the airway would be somewhere between T1-T2. Wong et al in 2008 published that the sternal notch to the carina represents $60 \%$ of the vocal cord to the carina distance ${ }^{7}$. T1 is located just below the sternal notch, it can thus be assumed that $\mathrm{T} 1$ is the mid point of the airway (vocal cord to the carina) Rotschild et al in 1999 suggested that the midtracheal position (midpoint of vocal cord to carina distance) is safe for both $<1000 \mathrm{gm}$ and $>1000 \mathrm{gms}$ infants based on $90^{\text {th }}$ centile of changes in ETT position with maximum flexion and extension².

It is widely accepted that the midtracheal position is the ideal. Some have used a point halfway between inferior clavicle and carina on a chest radiograph ${ }^{3,5}$ while others have defined it at the level of the $1 \mathrm{st}$ or the 2 nd thoracic vertebrae ${ }^{1,4}$.

The problem with estimating the midtracheal position as a midpoint between the clavicle and carina is that this will not be midtracheal and will insert ETT deeper than required into the airway that might increase the risk of complications. Moreover the level of the clavicle varies with position at different times in the same patient ${ }^{1}$ thus making the estimation inaccurate.

\section{References}

1. Blayney MP, Logan DR. First thoracic vertebral body as reference for endotracheal tube placement. Arch Dis Child 1994;71: F32-5.

2. Rotschild A, Chitayat D, Puterman ML, Phang MS, Ling, Baldwin V. Optimal positioning of endotracheal tubes for ventilation of preterm infants. Am J Dis Child 1991;145:1007-12.

3. Peterson J, Johnson N, Deakins K, Wilson-Costello D, Jelovsek JE, Chatburn R. Accuracy of the 7-8-9 rule for endotracheal tube placement in the neonate. $J$ Perinatol 2006;26:333-36.

4. Tochen ML. Orotracheal intubation in the newborn infant: a method for determining depth of tube insertion. J Pediatr 1979;95:1050-51.

5. G. J. Noback, M.A., Ph.D. The developmental topography of the larynx, trachea lungs in the fetus, new-, infant and child. Am J Dis Child 1923;26(6):515533

6. P. A. Hudgins, J. Siegel, I. Jacobs, and C. R. Abramowsky. The Normal Pediatric Larynx on CT and MR. Am J Neuroradiology 1997;18:239-45.

7. David T. Wong, MD, Hao Weng, MD, Eunice Lam, Hai-Bao Song, MD, Jin Liu, MD. Lengthening of the Trachea During Neck Extension: Which Part of the Trachea Is Stretched? Anesthesia and Analgesia 2008;107:989-93.

\section{How to cite this article?}

Sakhuja P, Whyte H, Finan E. Accuracy of 7-8-9 Rule: Neonatal Endotracheal Intubation. J Nepal Paediatr Soc 2012;32(1):93. 